\title{
Strength Evaluation of a Bogie Frame by Different Methods
}

\author{
Daoyun Chen ${ }^{1,}$, Shouguang Sun ${ }^{2}$, Qiang Li $^{2}$ \\ ${ }^{1}$ Key Laboratory of Conveyance and Equipment (Ministry of Education), East China Jiaotong University, Nanchang 330013, China \\ ${ }^{2}$ School of Mechanical,Electronic and Control Engineering, Beijing Jiaotong University, Beijing 100044, China
}

*Corresponding Author: Daoyun Chen, E-mail address:13116326@bjtu.edu.cn

Abstract:

Some crucial loads that current strength design specifications have not taken into ac-count are also considered when assessing the strength of a bogie frame. Calculation methods of these loads come from load analysis. Finite element simulation and fa-tigue test rig have been used to assess static strength and fatigue strength of a bogie frame. In addition to the two methods, actual running test is also used to assess bogie frame fatigue strength. In finite element simulation method, endurance limit and modified Goodman fatigue limit diagram are two important tools to judge whether fatigue strength of a bogie frame meets requirement. In actual running test method, Miner linear cumulative damage rule is used to assess bogie frame fatigue strength. Endurance limit and modified Goodman fatigue limit diagram are two effective tools to judge fatigue strength of the frame. For the measured dynamic stress data, Miner linear cumulative damage rule seems to be very effective when judging fatigue strength of the frame. All the above methods have proved that static and fatigue strength of the tested bogie frame meets requirement.

Keywords: Strength; Bogie frame; Finite elements; Fatigue test rig; Actual running test

Citation: D.Y. Chen, S.G. Sun, Q. Li, Strength Evaluation of a Bogie Frame by Different Methods. Mech Eng Sci, 2019,1(1): 54-64. https://doi. org/10.33142/me.v1i1.662

\section{Introduction}

Bogie frame, one of the most important high-speed train load-bearing components, is located between wheelsets and train carriage. Bogie frame belongs to typical frame type structure and it has very complex loading conditions. To some extent, whether structural strength meets requirements of relevant regulations directly determines safety of high-speed train. Therefore, it is very necessary to assess bogie frame strength. There are a variety of structural strength evaluation standards of bogie frame in the world today such as EN $13749^{[1]}$, UIC 615-4 ${ }^{[2]}$ and JIS E $4207{ }^{[3]}$. These standards have made clear experimental rules of bogie frame's static strength and fatigue strength. According to these standards, loads applying on a bogie frame mainly consist of vertical load and transverse load. Calculation methods of these loads are also listed by formulas. By using of these standards to assess bogie frame strength can get satisfactory results ${ }^{[4-7]}$. However, loading condition of bogie frame is extremely complex. Only using two kinds of load and neglecting the other loads to analyze bogie frame strength will get risk assessment results.

In order to accurately reflect loading condition of bogie frame and assess bogie frame strength, this paper calculates vertical loads, transverse loads, longitudinal loads, motor inertia loads, gearbox hanger loads, brake friction loads and anti-side-rolling torsion pole loads to evaluate bogie frame strength.
In this paper, strength evaluation of bogie frame mainly consists of static strength evaluation and fatigue strength evaluation. Static strength evaluation is operated by means of finite element simulation and load testing on test rig. Fatigue strength evaluation is operated by means of finite element simulation, load testing on test rig and train running test on actual railway.

\section{Load calculation method}

The studied bogie frame mainly consists of two side beams and two transverse beams. Various kinds of component mounting base are installed on the frame so that loads are very complicated. Four ends of the frame connect with axle box springs and four locating bases connect with axle box rotary arms.

Loading condition of the bogie frame is shown in Figure 1. Vertical loads and transverse loads can be calculated from formulas in EN13749. Calculation methods of the other types of load are deduced from load analysis.

2.1. Vertical loads

Vertical loads are applied to each side frame. According to EN13749, the load that each side frame withstand is calculated as (1):

$$
F_{z 1 \max }=F_{z 2 \max }=\frac{1.4 g}{2 n_{b}}\left(M_{v}+C_{1}-2 m^{+}\right)
$$




\begin{tabular}{|c|c|c|c|}
\hline \multicolumn{4}{|c|}{ Nomenclature } \\
\hline $\mathrm{F}_{\mathrm{z} 1}, \mathrm{~F}_{\mathrm{z} 2}$ & Vertical loads acting on each side frame & $\mathrm{F}_{\mathrm{zbrake}}$ & Vertical load caused by braking load \\
\hline $\mathrm{C}_{1}$ & $\begin{array}{l}\text { The mass of the passengers under overload } \\
\text { condition }\end{array}$ & $\mathrm{a}_{\mathrm{bmax}}$ & Maximum braking deceleration \\
\hline$M_{v}$ & Net mass of the train body & $\mathrm{R}$ & Radius of wheel \\
\hline $\mathrm{n}_{\mathrm{b}}$ & Number of each carriage bogie & $\mathrm{R}_{\mathrm{f}}$ & Friction radius of brake disk \\
\hline $\mathrm{m}^{+}$ & Mass of the bogie & $\mathrm{K}$ & Stiffness of air spring \\
\hline $\mathrm{n}_{\mathrm{e}}$ & Number of each bogie axle & $\mathrm{F}_{\text {anti }}$ & Anti-side-rolling torsion pole load \\
\hline $\mathrm{F}_{\mathrm{y}}$ & Transverse load acting on bogie frame & $\mathrm{C}$ & Damp of second vertical shock absorber \\
\hline $\mathrm{F}_{\mathrm{x}}$ & Longitudinal load acting on bogie frame & $\mathrm{L}_{\text {anti }}$ & $\begin{array}{l}\text { Transverse pitch between two anti-side-rolling } \\
\text { torsion pole seats }\end{array}$ \\
\hline$a_{x}$ & Longitudinal impact acceleration of bogie & á & Side-rolling angle of train carriage body \\
\hline$a_{\text {ver }}$ & Vertical vibration acceleration of motor & $\hat{a}$ & Torsion angle of torsion pole \\
\hline$a_{\text {tra }}$ & Transverse vibration acceleration of motor & $\mathrm{L}$ & Arm length of torsion bar \\
\hline$a_{\text {lon }}$ & Longitudinal vibration acceleration of motor & $\mathrm{T}_{\mathrm{r}}$ & Torsional rigidity of torsion pole \\
\hline $\mathrm{I}_{\mathrm{ver}}$ & Vertical load of motor caused by inertia & $\mathrm{o}_{1}$ & Major principal stress \\
\hline $\mathrm{I}_{\text {tra }}$ & Transverse load of motor caused by inertia & $\dot{o}_{2}$ & Secondary principal stress \\
\hline $\mathrm{I}_{\text {lon }}$ & Longitudinal load of motor caused by inertia & $\mathrm{o}_{3}$ & Third principal stress \\
\hline $\mathrm{M}_{\mathrm{m}}$ & Mass of motor & ó von $_{\text {von }}$ & Vonmises stress \\
\hline $\mathrm{F}_{\mathrm{gz}}$ & $\begin{array}{l}\text { Gear box hanger load caused by short circuit } \\
\text { torque of motor }\end{array}$ & $\mathrm{K}_{\mathrm{n}}$ & Normalized constant \\
\hline $\mathrm{L}_{\tan }$ & $\begin{array}{l}\text { Orthogonal distance between hanger rod center } \\
\text { line and axle center line }\end{array}$ & $\ddot{0}$ & $\begin{array}{l}\text { Variable to adjust the proportion of each distri- } \\
\text { bution function in the combined distribution }\end{array}$ \\
\hline $\mathrm{F}_{1}$ & Reactive load applying on driving gear shaft & $\mathrm{f}(\mathrm{x})_{1}$ & $\begin{array}{l}\text { Probability density function of Weibull distri- } \\
\text { bution }\end{array}$ \\
\hline $\mathrm{T}_{\operatorname{mmax}}$ & Short circuit torque of motor & $\mathrm{f}(\mathrm{x})_{2}$ & $\begin{array}{l}\text { Probability density function of lognormal } \\
\text { distribution }\end{array}$ \\
\hline $\mathrm{R}_{1}$ & Radius of driving gear & $f(x)$ & $\begin{array}{l}\text { Probability density function of combined dis- } \\
\text { tribution }\end{array}$ \\
\hline $\mathrm{R}_{2}$ & Radius of driven gear & $\mathrm{n}_{\mathrm{i}}$ & Cycle numbers of each level \\
\hline $\mathrm{i}$ & Transmission ratio & $\mathrm{C}_{3}, \mathrm{~m}$ & $\mathrm{~S}-\mathrm{N}$ curve parameters \\
\hline $\mathrm{F}_{\mathrm{gzmax}}$ & Maximum gear box hanger load & Ó $_{-1 \mathrm{i}}$ & Stress amplitude of each level \\
\hline $\mathrm{M}_{\mathrm{g}}$ & Mass of gearbox & $\mathrm{D}$ & Miner damage \\
\hline$F_{x}^{\prime}$ & Reactive load of $F_{x}$ & $\mathrm{~N}_{\mathrm{i}}$ & Fatigue life under certain stress level \\
\hline
\end{tabular}

\subsection{Transverse loads}

According to EN13749, transverse loads are calculated as (2):

$F_{y \max }=2\left[10^{4}+\frac{\left(M_{v}+C_{1}\right) g}{3 n_{e} n_{b}}\right]$

Transverse loads are distributed on lateral stop and air spring seat.

\subsection{Longitudinal loads}

Longitudinal loads are calculated according to Newton's Second Law of Motion. The formula is listed as (3):

$F_{x \max }=m^{+} a_{x \max }$
The acting positions of longitudinal loads are two traction rod seats.

\subsection{Motor inertia loads}

Considering the influence of vibration acceleration, motor inertia loads are listed as follows:

$I_{v e r}=M_{m} a_{v e r}$

$I_{\text {tra }}=M_{m} a_{\text {tra }}$

$I_{l o n}=M_{m} a_{l o n}$

\subsection{Gearbox hanger loads}

Gearbox hanger loads are caused by two main aspects. One of the aspects is the load that caused by short circuit torque of mo- 
tor. This torque is also called starting torque. When power is connected to motor and motor has yet to start turning, wires between stator and rotor are equivalent to short circuit. The torque is very large at this moment which can be up to 2.2 times bigger than rated load torque of motor.

Load diagram under the condition of motor short circuit is shown in Figure 2.

As can be seen from Figure 2, the gearbox hanger is connected to case body. Driving gear is connected to motor and driven gear is connected to hollow axle of high-speed train. When motor runs, driven gear is driven to rotate by driving gear. As a result, motor torque is passed to driven gear. According to principle of mechanics, all the torques are converted to loads applying on driving gear shaft, hollow axle of high-speed train and gearbox hanger. According to force moment equilibrium principle at central point of driven gear, force moment equilibrium equation can be listed as follows: $F_{g z} L_{\text {tan }}=\left(R_{1}+R_{2}\right) F_{1}=\left(R_{1}+R_{2}\right) \frac{T_{\text {mmax }}}{R_{1}}$

Therefore,

$$
F_{g z}=\frac{T_{\text {mmax }}\left(R_{1}+R_{2}\right)}{R_{1} L_{\text {tan }}}=\frac{(1+i) T_{\text {mmax }}}{L_{\text {tan }}}
$$

Considering vibration load of gearbox, maximum load applying on gearbox hanger is

$$
F_{g z \max }=\frac{(1+i) T_{\max }}{L_{\text {tan }}}+\frac{M_{g} a_{v e r}}{3}
$$

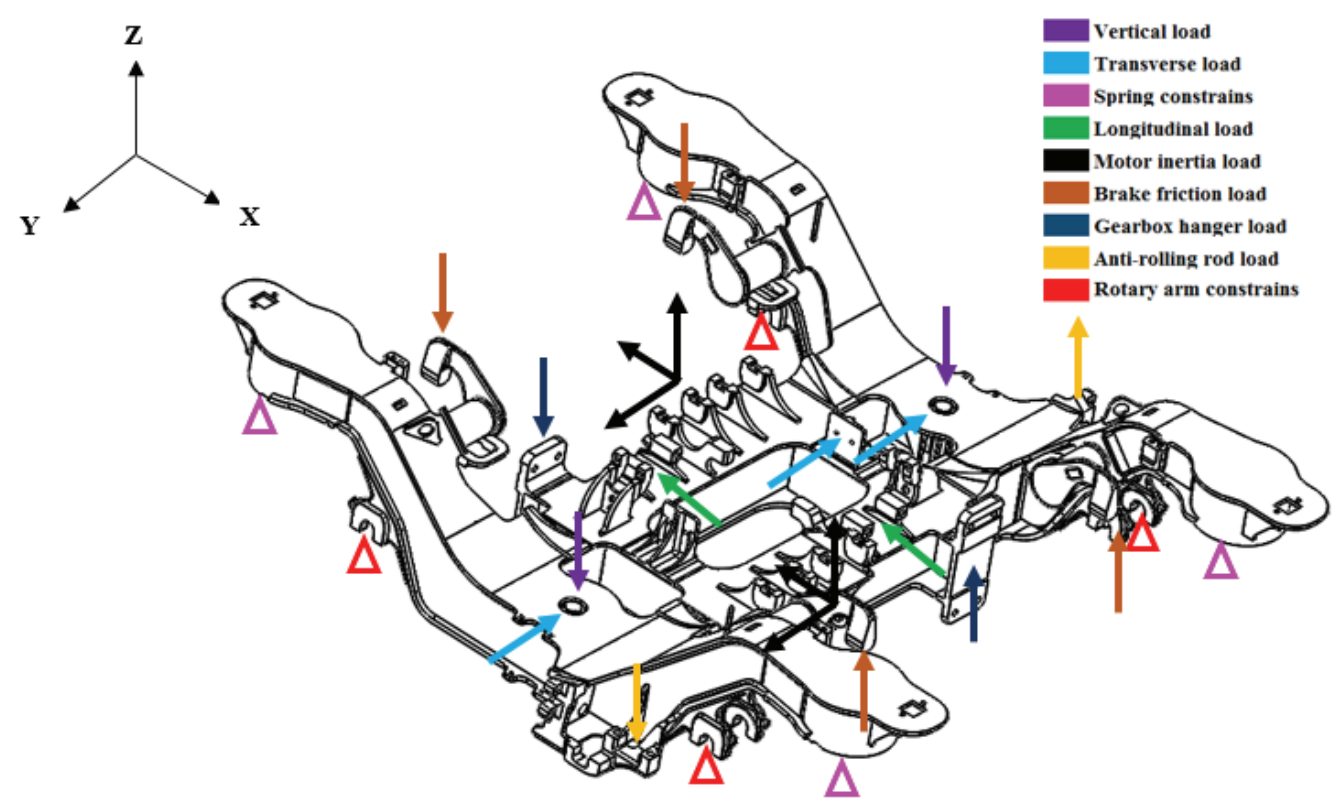

Figure 1. Bogie frame load diagram

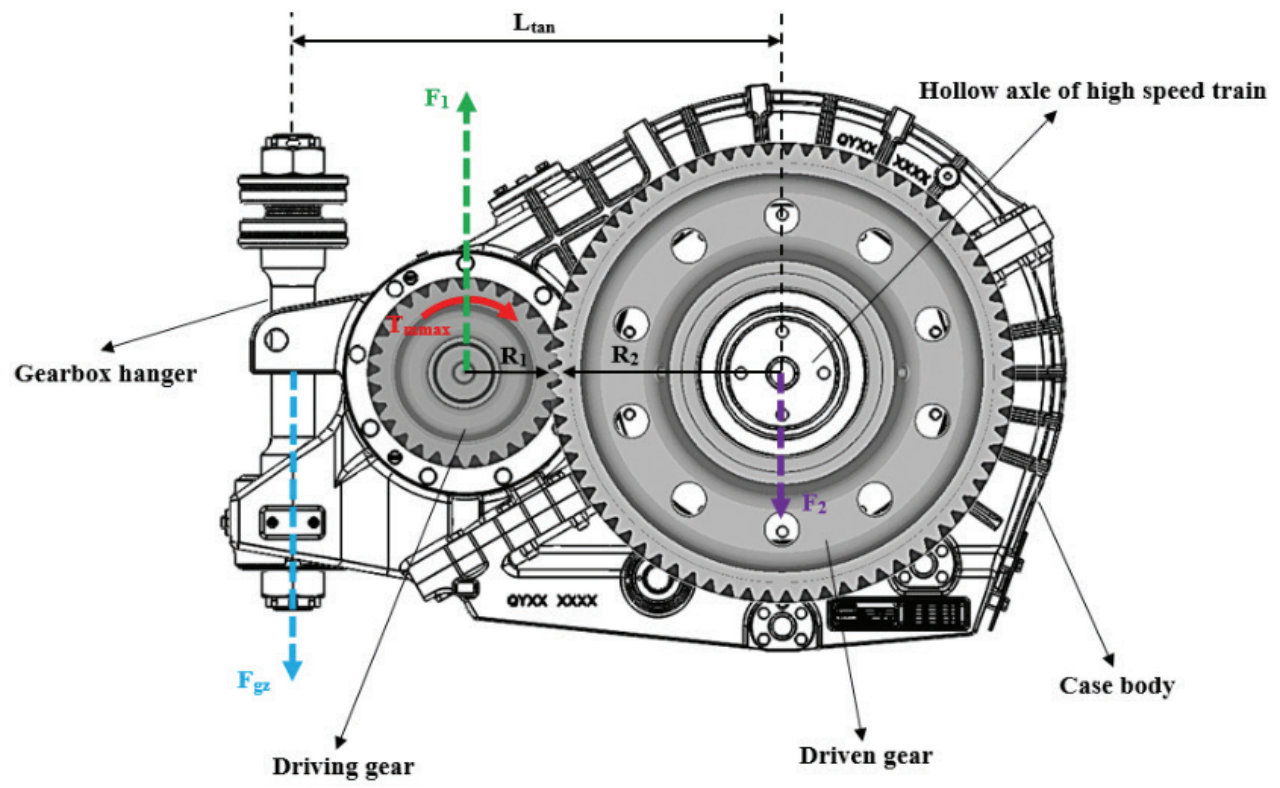

Figure 2. Load diagram of gearbox 


\subsection{Brake friction loads}

The brake mode of bogie in this paper is wheel disc brake. When brake calipers act on brake discs, wheel loads can be considered as dynamic balance. The load diagram is shown as Figure 3.

According to EN13749, the longitudinal loads of bogie frame can be calculated as (10):

$F_{x}=a_{b \max } \frac{M_{v}+C_{1}}{n_{b}}$

According to moment balance principle, friction load of each axle that caused by maximum braking load under emergency braking condition is

$F_{z b r a k e}=\frac{F_{x} R}{4 R_{f}}$

\subsection{Anti-side-rolling torsion pole loads}

The load diagram of anti-side-rolling torsion pole is shown as Figure 4.
On the basis of load balance, anti-side-rolling torsion pole load can be calculated as (12):

$F_{\text {anti }}=\frac{T_{r} \beta}{L_{\text {anti }} \cos \beta}$

The geometrical relationship between side-rolling angle of train carriage body and torsion angle of torsion pole is

$\frac{L_{\text {anti }}}{2} \sin \alpha \approx L \sin \beta$

\section{Static strength evaluation of bogie frame}

The purpose of static strength assessment is to test the stresses of bogie frame under static exceptional loads so that whether static strength can meet requirements will be judged. If stresses are lower than yield stress of the frame, then the frame can be considered to meet requirements of static strength. In this paper, two methods, that is finite element simulation and load testing on test rig, are used to evaluate static strength of bogie frame.

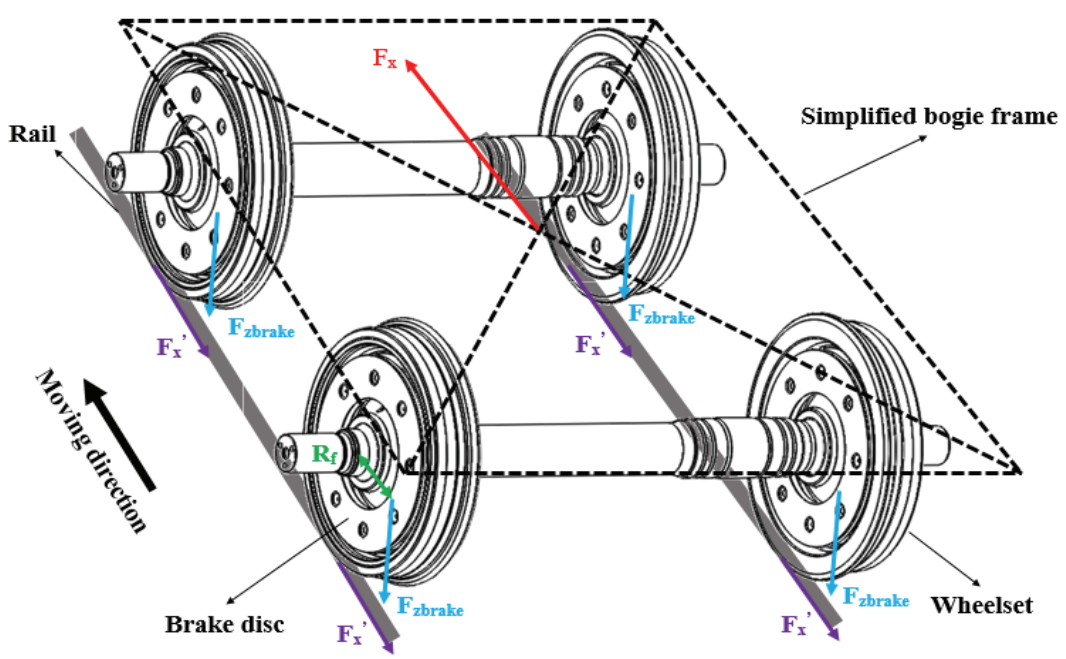

Figure 3. Load diagram of wheelset

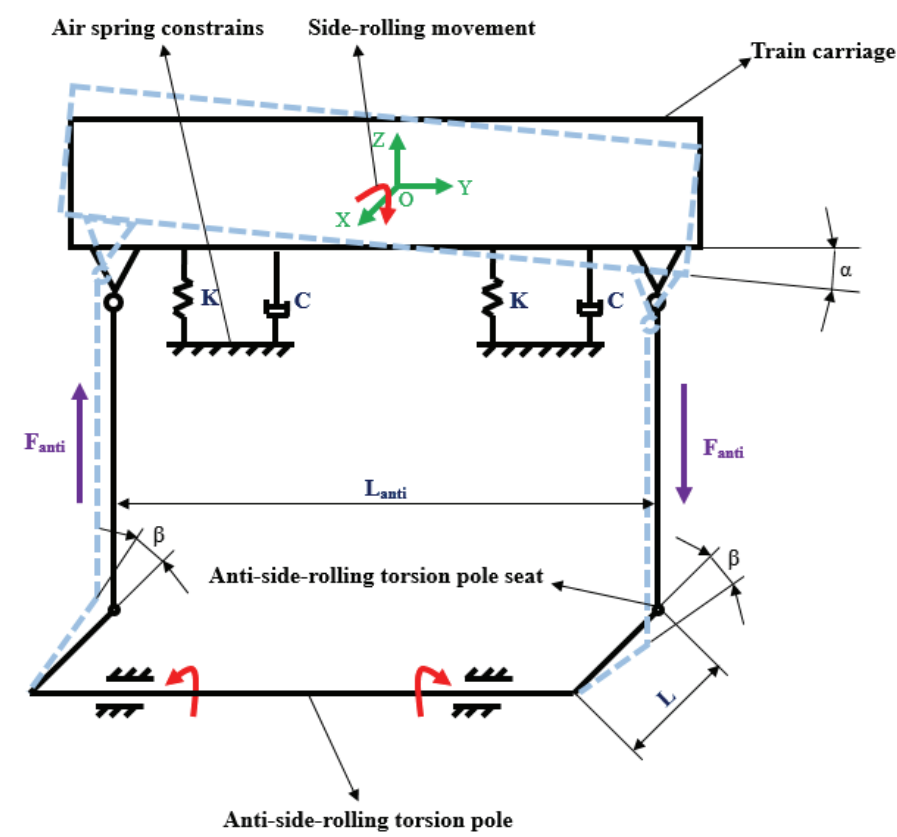

Figure 4. Load diagram of anti-side-rolling torsion pole 
Therefore, anti-side-rolling torsion pole load can be modified as

$$
F_{\text {anti }}=\frac{T_{r} \arcsin \frac{L_{a n t i} \sin \alpha}{2 L}}{L_{\text {anti }} \sqrt{1-\left(\frac{L_{a n t i} \sin \alpha}{2 L}\right)^{2}}}
$$

3.1. Checking static strength of bogie frame by means of finite element simulation

Considering bogie parameters under exceptional conditions and formulas of each load, final load cases are listed in Table 1.

Through finite element calculation, there are five positions show maximum stress on the frame under 13 kinds of load case. The vonmises stress response of the results are shown in Figure 5.

Table 2 shows frame material mechanics property parameters. After comparison of Figure 5 and Table 2, it can be seen clearly that all the stress values of the selected measuring points are lower than yield limit of base metal. Therefore, the bogie frame has enough static strength. Figure 6 displays finite element calculation results under the eighth load case which is the worst load conditions in the total 13 load cases.

As can be seen from Figure 6, the maximum stress occurs in gearbox reinforcing plate. The value of its vonmises stress is 319.6 MPa.

Table 1: Supernormal load values under different load cases.

\begin{tabular}{|c|c|c|c|c|c|c|c|c|c|c|c|c|c|c|c|}
\hline \multirow{2}{*}{ Load type } & \multirow{2}{*}{\multicolumn{2}{|c|}{ Location }} & \multicolumn{13}{|c|}{ Load case } \\
\hline & & & 1 & 2 & 3 & 4 & 5 & 6 & 7 & 8 & 9 & 10 & 11 & 12 & 13 \\
\hline \multirow{2}{*}{ Vertical load } & \multicolumn{2}{|c|}{ Left side beam } & -183.5 & -183.5 & -183.5 & -183.5 & -183.5 & -183.5 & -183.5 & -183.5 & -183.5 & -183.5 & -183.5 & -183.5 & -183.5 \\
\hline & \multicolumn{2}{|c|}{ Right side beam } & -183.5 & -183.5 & -183.5 & -183.5 & -183.5 & -183.5 & -183.5 & -183.5 & -183.5 & -183.5 & -183.5 & -183.5 & -183.5 \\
\hline \multirow{2}{*}{ Transverse load } & \multicolumn{2}{|c|}{ Air spring seat } & 0 & 0 & 0 & -14.6 & 14.6 & 0 & 0 & 0 & 0 & 0 & 0 & 0 & 0 \\
\hline & \multicolumn{2}{|c|}{ Lateral stop } & 0 & 0 & 0 & -120.9 & 120.9 & 0 & 0 & 0 & 0 & 0 & 0 & 0 & 0 \\
\hline \multirow{2}{*}{$\begin{array}{l}\text { Longitudinal } \\
\text { load }\end{array}$} & \multicolumn{2}{|c|}{ Front } & 0 & 126.4 & -126.4 & 0 & 0 & 66.7 & -66.7 & 23.4 & -23.4 & 32.2 & -32.2 & 0 & 0 \\
\hline & \multicolumn{2}{|c|}{ Back } & 0 & 126.4 & -126.4 & 0 & 0 & 23.4 & -23.4 & 66.7 & -66.7 & 32.2 & -32.2 & 0 & 0 \\
\hline \multirow{2}{*}{ Anti-rolling rod } & \multicolumn{2}{|c|}{ Left } & 0 & 0 & 0 & 60 & -60 & 0 & 0 & 0 & 0 & 0 & 0 & 0 & 0 \\
\hline & \multicolumn{2}{|c|}{ Right } & 0 & 0 & 0 & -60 & 60 & 0 & 0 & 0 & 0 & 0 & 0 & 0 & 0 \\
\hline \multirow{2}{*}{ Brake friction } & \multicolumn{2}{|c|}{ Front } & 0 & 0 & 0 & 0 & 0 & 0 & 0 & 0 & 0 & 48.6 & -48.6 & 0 & 0 \\
\hline & \multicolumn{2}{|c|}{ Back } & 0 & 0 & 0 & 0 & 0 & 0 & 0 & 0 & 0 & -48.6 & 48.6 & 0 & 0 \\
\hline \multirow{2}{*}{ Gearbox hanger } & \multicolumn{2}{|c|}{ Front } & 0 & 0 & 0 & 0 & 0 & 156.1 & -156.1 & 47.8 & -47.8 & 0 & 0 & 0 & 0 \\
\hline & \multicolumn{2}{|c|}{ Back } & 0 & 0 & 0 & 0 & 0 & -47.8 & 47.8 & -156.1 & 156.1 & 0 & 0 & 0 & 0 \\
\hline \multirow{6}{*}{ Motor inertia } & \multirow{2}{*}{ Vertical } & Front & 0 & 0 & 0 & 0 & 0 & 0 & 0 & 0 & 0 & 0 & 0 & -85.7 & -85.7 \\
\hline & & Back & 0 & 0 & 0 & 0 & 0 & 0 & 0 & 0 & 0 & 0 & 0 & -85.7 & -85.7 \\
\hline & \multirow{2}{*}{ Lateral } & Front & 0 & 0 & 0 & 0 & 0 & 0 & 0 & 0 & 0 & 0 & 0 & 39 & -39 \\
\hline & & Back & 0 & 0 & 0 & 0 & 0 & 0 & 0 & 0 & 0 & 0 & 0 & 39 & -39 \\
\hline & \multirow{2}{*}{$\begin{array}{l}\text { Longitu- } \\
\text { dinal }\end{array}$} & Front & 0 & 0 & 0 & 0 & 0 & 0 & 0 & 0 & 0 & 0 & 0 & 23.4 & -23.4 \\
\hline & & Back & 0 & 0 & 0 & 0 & 0 & 0 & 0 & 0 & 0 & 0 & 0 & 23.4 & -23.4 \\
\hline
\end{tabular}

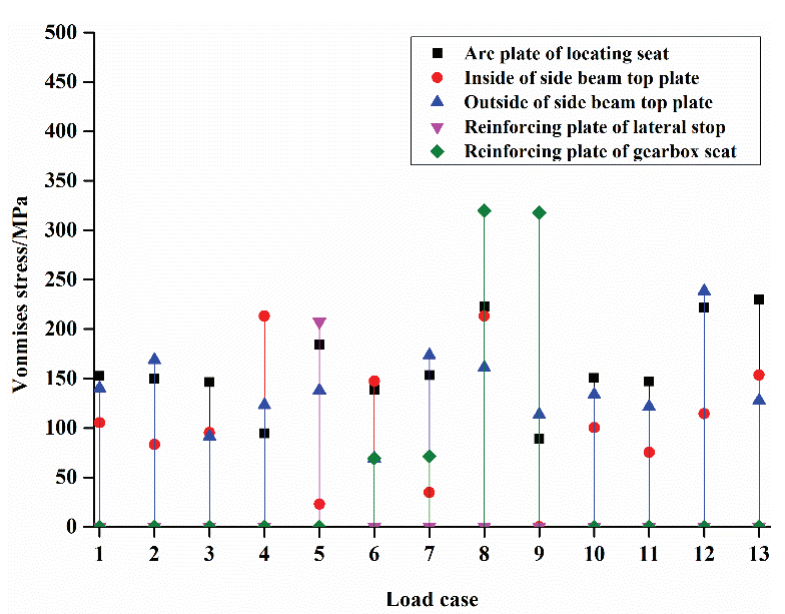

Table 2: Material mechanics property parameter

\begin{tabular}{ll}
\hline Frame material & S355J2G \\
\hline Tensile strength $(\mathrm{MPa})$ & 510 \\
Yield strength $(\mathrm{MPa})$ & 355 \\
$\begin{array}{l}\text { Endurance limit of S-N curve } \\
\text { by } 10^{7} \text { cycles }(\mathrm{MPa})\end{array}$ & 130 \\
$\begin{array}{l}\text { Elastic modulus }(\mathrm{MPa}) \\
\text { Poisson's ratio }\end{array}$ & 206000 \\
\hline
\end{tabular}

Figure 5. Response of five locations of maximum vonmises stress under different supernormal load cases. 


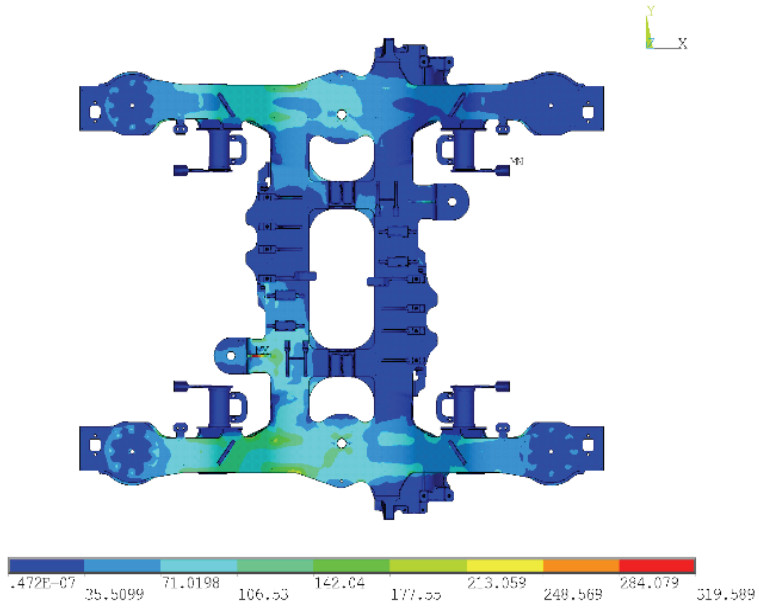

(a) The complete figure

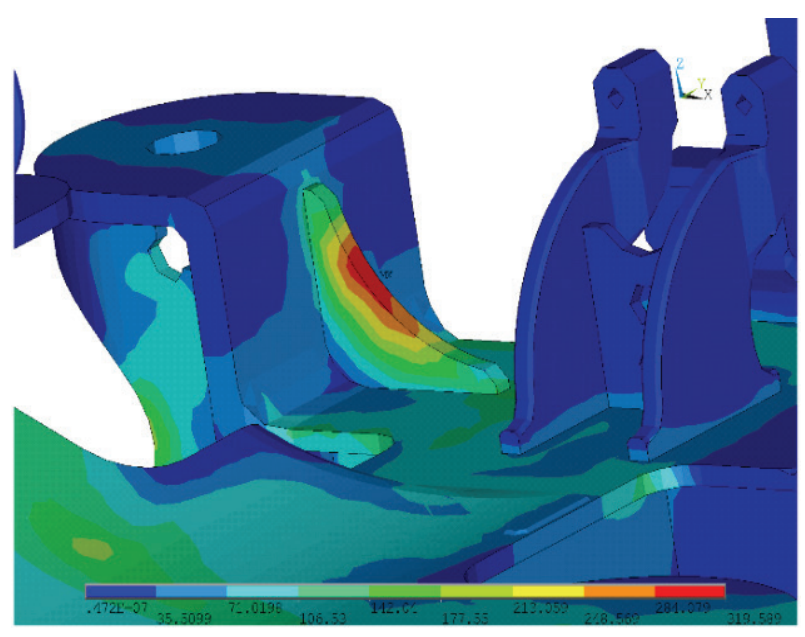

(b) The local figure of the reinforcing plate

Figure 6. Finite element results of the worst load cases.

Table 3: Von Mises stress results comparison between FE and test( $\mathrm{MPa})$.

\begin{tabular}{|c|c|c|c|c|c|c|c|c|c|c|c|c|c|c|}
\hline \multirow{2}{*}{ Location } & \multirow{2}{*}{$\begin{array}{l}\text { Meth- } \\
\text { od }\end{array}$} & \multicolumn{13}{|c|}{ Load case } \\
\hline & & 1 & 2 & 3 & 4 & 5 & 6 & 7 & 8 & 9 & 10 & 11 & 12 & 13 \\
\hline \multirow{2}{*}{$\begin{array}{l}\text { Arc plate of } \\
\text { locating seat }\end{array}$} & $\mathrm{FE}$ & 152.5 & 150.2 & 146.3 & 94.7 & 184.2 & 138.4 & 153.3 & 223.1 & 89.2 & 150.5 & 147.2 & 221.6 & 230.2 \\
\hline & Test & 154.5 & 154.2 & 150.3 & 87.7 & 180.2 & 130.4 & 152.3 & 221.1 & 95.2 & 156.5 & 147.2 & 228.6 & 235.2 \\
\hline \multirow{2}{*}{$\begin{array}{l}\text { Inside of side } \\
\text { beam top plate }\end{array}$} & $\mathrm{FE}$ & 105.3 & 83.2 & 95.4 & 213.1 & 23.1 & 147.2 & 34.7 & 213.1 & 0 & 100.3 & 75.3 & 114.3 & 153.5 \\
\hline & Test & 93.3 & 80.2 & 87.4 & 207.1 & 23.1 & 144.2 & 32.7 & 206.1 & 10 & 100.3 & 75.3 & 113.3 & 151.5 \\
\hline \multirow{2}{*}{$\begin{array}{l}\text { Outside of side } \\
\text { beam top plate }\end{array}$} & FE & 140.2 & 168.9 & 91.4 & 123.3 & 138.1 & 69.2 & 173.7 & 161.2 & 113.6 & 133.8 & 121.6 & 238.5 & 127.9 \\
\hline & Test & 149.2 & 178.9 & 94.4 & 126.3 & 145.1 & 65.2 & 171.7 & 156.2 & 120.6 & 129.8 & 118.6 & 234.5 & 118.9 \\
\hline \multirow{2}{*}{$\begin{array}{l}\text { Reinforcing plate } \\
\text { of lateral stop }\end{array}$} & $\mathrm{FE}$ & 0 & 0 & 0 & 0 & 207.2 & 0 & 0 & 0 & 0 & 0 & 0 & 0 & 0 \\
\hline & Test & 0 & 0 & 0 & 0 & 201.4 & 0 & 0 & 0 & 0 & 0 & 0 & 0 & 0 \\
\hline \multirow{2}{*}{$\begin{array}{l}\text { Reinforcing plate } \\
\text { of gearbox seat }\end{array}$} & $\mathrm{FE}$ & 0 & 0 & 0 & 0 & 0 & 69.2 & 71.4 & 319.6 & 317.7 & 0 & 0 & 0 & 0 \\
\hline & Test & 0 & 0 & 0 & 0 & 0 & 67.2 & 71.4 & 308.6 & 310.7 & 0 & 0 & 0 & 0 \\
\hline
\end{tabular}

3.2 Checking static strength of bogie frame by means of load testing on test rig

The full-size bogie frame was installed on MTS fatigue test rig. The biggest test load of actuator is $1000 \mathrm{kN}$. Around the test rig, there were no high-intensity magnetic field, noise and calibration which could affect the testing accuracy. The temperature was kept at about $25^{\circ} \mathrm{C}$ and air relative humidity was not greater than $80 \%$. All the loads were applied by actuators. The type and value of the applied loads were consistent with finite element calculation. The complete experiment equipment is shown in Figure 7.

After applying loads on the frame, it can be seen in real time that stress values of all measuring points were lower than yield limit of base metal. Therefore, it was confirmed that static strength meets the requirements from the angle of experiment. Table 3 shows the good consistence between FE and test under supernormal load cases.

\section{Fatigue strength evaluation of bogie frame}

4.1. Checking fatigue strength of bogie frame by means of finite element simulation

4.1.1 Normal service loads calculation
Operating loads of bogie frame are needed to check fatigue strength. The calculation formulas of operating loads are consistent with exceptional loads. The only difference between them is that values of the parameters in those formulas have to change according to exceptional loads or normal service loads.

The normal operating load values under different load cases are shown in Table 4 and calculation results of finite element simulation are listed in Table 5

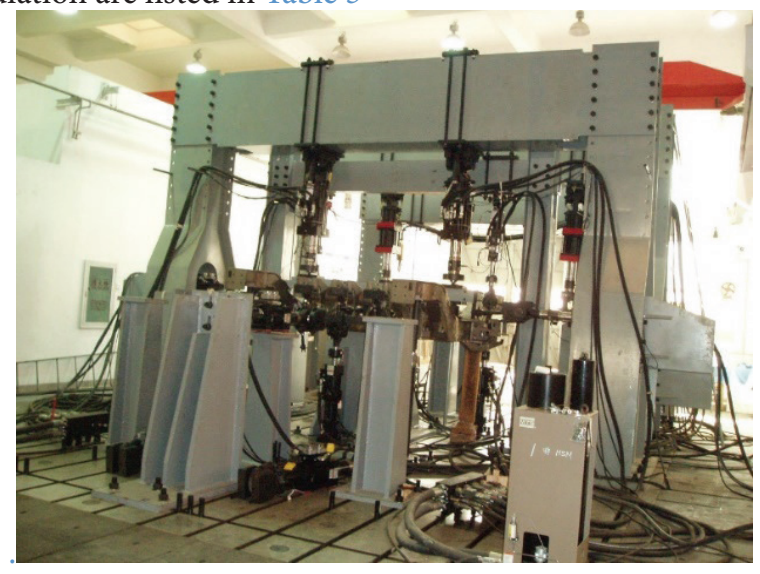

Figure 7. MTS fatigue test rig. 
Table 4: Normal operating load values under different load cases.

\begin{tabular}{|c|c|c|c|c|c|c|c|c|c|c|c|}
\hline \multirow{2}{*}{ Load type } & \multirow{2}{*}{\multicolumn{2}{|c|}{ Location }} & \multicolumn{9}{|c|}{ Load case } \\
\hline & & & 1 & 2 & 3 & 4 & 5 & 6 & 7 & 8 & 9 \\
\hline \multirow{2}{*}{ Vertical load } & \multirow{2}{*}{\multicolumn{2}{|c|}{$\begin{array}{l}\text { Left side beam } \\
\text { Right side beam }\end{array}$}} & -124.5 & -112.1 & -112.1 & -161.9 & -161.9 & -87.2 & -87.2 & -136.9 & -136.9 \\
\hline & & & -124.5 & -87.2 & -87.2 & -136.9 & -136.9 & -112.1 & -112.1 & -161.9 & -161.9 \\
\hline \multirow{2}{*}{ Transverse load } & \multicolumn{2}{|c|}{ Air spring seat } & 0 & 0 & 14.6 & 0 & 14.6 & 0 & -14.6 & 0 & -14.6 \\
\hline & \multicolumn{2}{|c|}{ Lateral stop } & 0 & 0 & 68.7 & 0 & 68.7 & 0 & -68.7 & 0 & -68.7 \\
\hline \multirow{2}{*}{ Longitudinal load } & \multicolumn{2}{|c|}{ Front } & 0 & 16.7 & 16.7 & 16.7 & 16.7 & 16.7 & 16.7 & 16.7 & 16.7 \\
\hline & \multicolumn{2}{|c|}{ Back } & 0 & 16.7 & 16.7 & 16.7 & 16.7 & 16.7 & 16.7 & 16.7 & 16.7 \\
\hline \multirow{2}{*}{ Anti-rolling rod } & \multicolumn{2}{|c|}{ Left } & 0 & 14.2 & 14.2 & 14.2 & 14.2 & 14.2 & 14.2 & 14.2 & 14.2 \\
\hline & \multicolumn{2}{|c|}{ Right } & 0 & 14.2 & -14.2 & -14.2 & -14.2 & -14.2 & -14.2 & -14.2 & -14.2 \\
\hline \multirow{2}{*}{ Brake friction } & \multicolumn{2}{|c|}{ Front } & 0 & 31.1 & 31.1 & 31.1 & 31.1 & 31.1 & 31.1 & 31.1 & 31.1 \\
\hline & \multicolumn{2}{|c|}{ Back } & 0 & 31.1 & -31.1 & -31.1 & -31.1 & -31.1 & -31.1 & -31.1 & -31.1 \\
\hline \multirow{2}{*}{ Gearbox hanger } & \multirow{2}{*}{\multicolumn{2}{|c|}{$\begin{array}{c}\text { Front } \\
\text { Back }\end{array}$}} & 0 & 34.2 & 34.2 & 34.2 & 34.2 & 34.2 & 34.2 & 34.2 & 34.2 \\
\hline & & & 0 & 34.2 & -34.2 & -34.2 & -34.2 & -34.2 & -34.2 & -34.2 & -34.2 \\
\hline \multirow{6}{*}{ Motor inertia } & \multirow{2}{*}{ Vertical } & Front & 0 & -36.8 & -36.8 & -36.8 & -36.8 & -36.8 & -36.8 & -36.8 & -36.8 \\
\hline & & Back & 0 & -36.8 & -36.8 & -36.8 & -36.8 & -36.8 & -36.8 & -36.8 & -36.8 \\
\hline & \multirow{2}{*}{ Lateral } & Front & 0 & -29.4 & -29.4 & -29.4 & -29.4 & -29.4 & -29.4 & -29.4 & -29.4 \\
\hline & & Back & 0 & -29.4 & -29.4 & -29.4 & -29.4 & -29.4 & -29.4 & -29.4 & -29.4 \\
\hline & \multirow{2}{*}{ Longitudinal } & Front & 0 & -23.4 & -23.4 & -23.4 & -23.4 & -23.4 & -23.4 & -23.4 & -23.4 \\
\hline & & Back & 0 & -23.4 & -23.4 & -23.4 & -23.4 & -23.4 & -23.4 & -23.4 & -23.4 \\
\hline
\end{tabular}

Table 5: Finite element simulation results under normal service loads.

\begin{tabular}{|c|c|c|c|c|c|c|c|c|c|c|c|}
\hline \multirow{2}{*}{ Location } & \multicolumn{9}{|c|}{ Load case } & \multirow{2}{*}{$\begin{array}{l}\text { Stress } \\
\text { range }\end{array}$} & \multirow{2}{*}{$\begin{array}{l}\text { Mean } \\
\text { stress }\end{array}$} \\
\hline & 1 & 2 & 3 & 4 & 5 & 6 & 7 & 8 & 9 & & \\
\hline Traction rod seat & 0 & 41.2 & 35.7 & 41.5 & 34.6 & 51.1 & 29.3 & 37.4 & 41.8 & 51.1 & 25.55 \\
\hline Motor suspension & 0 & 52.3 & 47.7 & 62.2 & 59.6 & 53.4 & 64.1 & 73.3 & 64.2 & 73.3 & 36.65 \\
\hline Anti-rolling rod seat & 0 & 37.7 & 66.3 & 82.9 & 63.6 & 71.2 & 85.4 & 89.6 & 97.4 & 97.4 & 48.7 \\
\hline Braking hanging brackets & 0 & 64.5 & 66.1 & 82.4 & 105.9 & 77.2 & 88.6 & 92.3 & 101.2 & 105.9 & 52.95 \\
\hline Arc plate of locating seat & 103.8 & 145.1 & 149.2 & 186.6 & 190.7 & 160.1 & 192.3 & 201.1 & 219.2 & 115.4 & 161.5 \\
\hline Inside of side beam top plate & 99.6 & 142.6 & 110.7 & 153.3 & 136.5 & 154.3 & 192.4 & 185.2 & 214.3 & 114.7 & 156.9 \\
\hline Outside of side beam top plate & 92.3 & 64.5 & 99.5 & 82.9 & 127.1 & 71.2 & 21.4 & 134.1 & 66.2 & 112.7 & 77.75 \\
\hline Reinforcing plate of lateral stop & 0 & 0 & 116.1 & 0 & 105.9 & 0 & 113.5 & 0 & 107.5 & 116.1 & 58.1 \\
\hline Reinforcing plate of gearbox seat & 0 & 75.6 & 66.3 & 69.3 & 84.7 & 71.2 & 85.4 & 44.7 & 73.1 & 85.4 & 42.7 \\
\hline
\end{tabular}

4.1.2 Fatigue strength evaluation method basing on endurance limit

It is well known that when steel is applied load that changes over time, the stress will also change over time. If the value of alternating stress exceeds an ultimate strength and lasts for a long term, material will be destroyed. The ultimate strength is called endurance limit. Therefore, material will not be destroyed if the stress amplitude is lower than endurance limit. As can be seen from Table 5, all measuring points' stress amplitudes are lower than endurance limit. As a result, fatigue strength of the bogie frame meets requirement.

4.1.3 Fatigue strength evaluation method basing on modified Goodman fatigue limit diagram

Modified Goodman fatigue limit diagram ${ }^{[8]}$ is a kind of simplified fatigue limit diagram. Based on linear empirical formula proposed by Goodman, actual fatigue limit stress lines are replaced by straight lines. This diagram is, in fact, a kind of fatigue damage stress envelope. If any stress points are located in the envelope, then fatigue fracture of the material will not occur after $\mathrm{N}$ times fatigue cycles. Based on material mechanics property parameters, the modified Goodman fatigue limit diagram is shown in Figure 8. At the same time, the stress points of finite element simulation result are also shown in Figure 8.

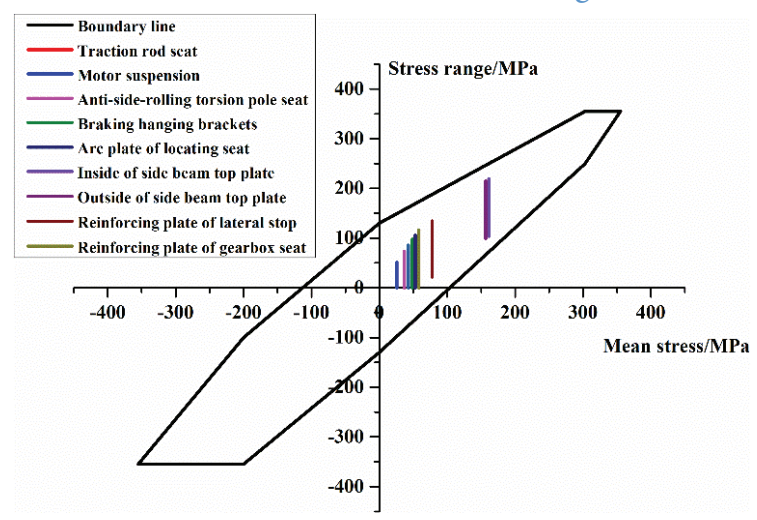

Figure 8. Goodman fatigue limit diagram 
It can be seen from Figure 8 that all stress points are located in the envelope of modified Goodman fatigue limit diagram. Therefore, fatigue strength of the bogie frame meets requirement.

4.2 Checking fatigue strength of bogie frame by means of load testing on test rig

The bogie frame was also installed on MTS fatigue test rig when operating fatigue strength test. There are three different stages during test and each frame load at each stage is composed of three different forms of load, that is static load, quasi-static load and dynamic load. The cycle number of quasi-static load in the first stage is 6 million. The cycle number of quasi-static load in the last two stages is all $2 \mathrm{~m}$. The quasi-static load cycles are normally reversed every 10 dynamic cycles. The dynamic load frequency is $2 \mathrm{~Hz}$. The load loading diagrams are shown in Figure 9 and Figure 10.

Figure 11 is operation interface of the fatigue test rig system. Through computer control, different types of load are applied on frame according to certain rules. At the same time, loading status of the frame can be monitored in real time. The fatigue test started in mid-November 2014 and ended in early April 2015. The bolts and test-ing tool were replaced several time during the whole test period. The magnetic powder inspection was operated after 2 million, 4 million, 6 million, 8 million and 10 million cycles respectively. The testing results showed that no fatigue crack was formed in the bogie frame.

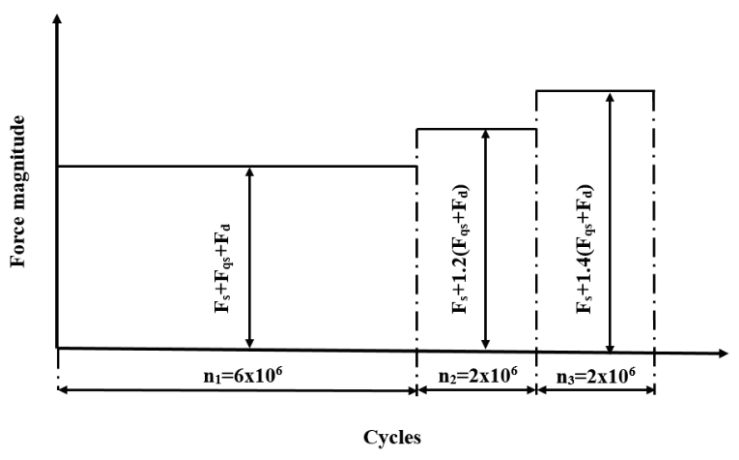

Figure 9. Variation of load magnitudes during test

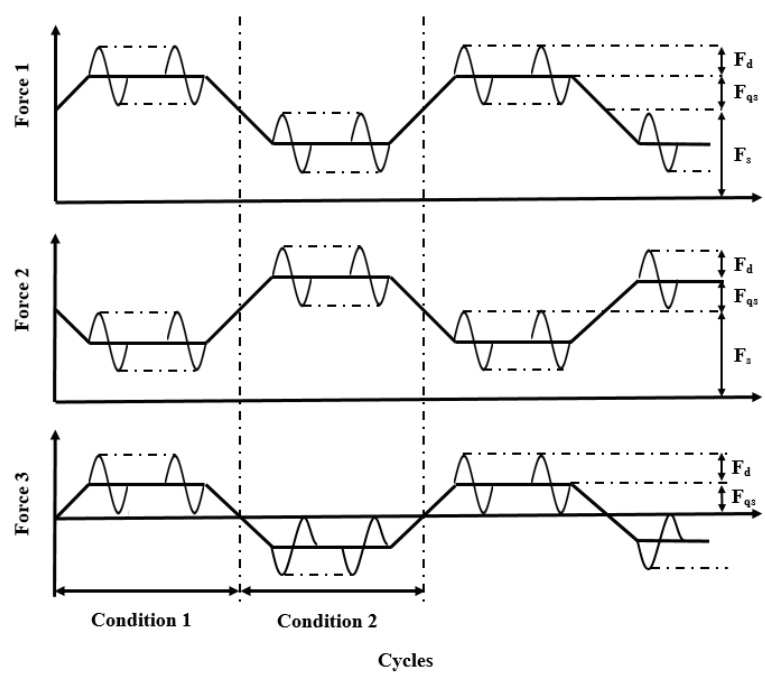

Figure 10. Variation of loads with respect to time

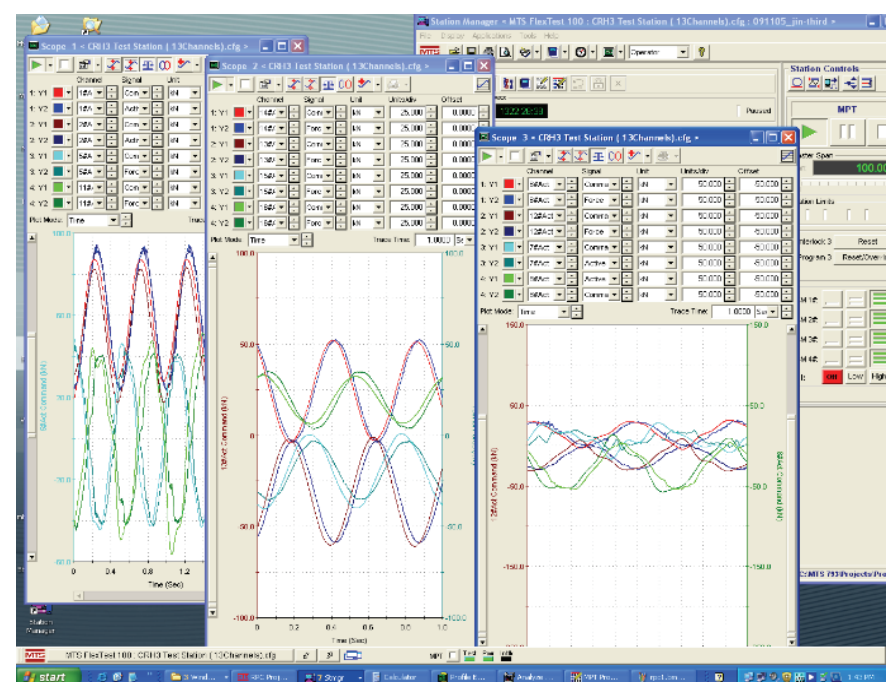

Figure 11. Computer control interface of fatigue test rig.

4.3. Checking fatigue strength of bogie frame by means of train running test on actual railway

In order to verify the frame's fatigue strength in the process of practical application, strain rosettes were pasted on fatigue critical parts of the bogie frame. Frame diagram of measuring points is shown in Figure 12. There are nine types of measuring point and twenty-eight positions of measuring point. All the strain gauges were protected by silica gel and were connected with IMC data acquisition system by wires. The IMC data acquisition system was placed in the train carriage, which is shown in Figure 13.

The tested train is a new kind of high-speed train which consists of eight train unit. The tested frame was installed in the first quarter of the head car. The installation position of the tested frame is shown in Figure 14.

The operation route is Beijing-Shanghai express railway which was opened in 2011. Total length of the railway is 1318 kilometers and the top speed of tested train is $350 \mathrm{~km} / \mathrm{h}$. The train ran a full round trip and a great deal of dynamic stress data was collected.

\subsubsection{Test data processing}

Although the test equipment has high accuracy and reliability, normal signal will still be difficult to avoid interference by various interference sources. Therefore, it is definitely necessary to process the signal before analysis. The signal processing process is shown in Figure 15.

\subsubsection{Statistical processing of dynamic stress signal}

Each strain rosette has three strain test channels. Three principal stresses of each measuring point can be gotten through certain conversion formula. Then vonmises stress can be calculated through the following formula:

$\sigma_{\text {von }}=\sqrt{\frac{\left(\sigma_{1}-\sigma_{2}\right)^{2}+\left(\sigma_{2}-\sigma_{3}\right)^{2}+\left(\sigma_{3}-\sigma_{1}\right)^{2}}{2}}$

There are a total of 28 measuring points' vonmises stress time domain data. These data cannot be directly used to judge fatigue strength of the frame. To make use of the measured data to check fatigue strength of the frame, rain-flow counting meth- 


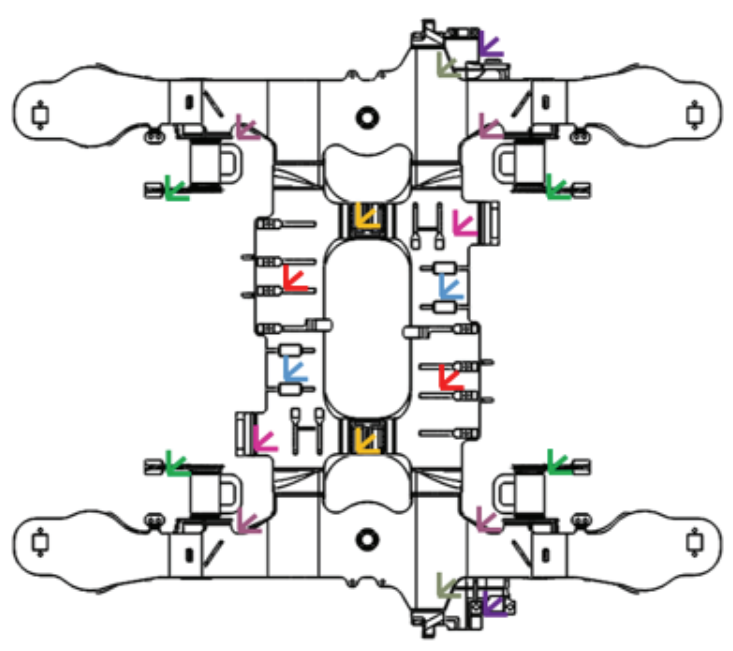

\begin{tabular}{|l|} 
Traction rod seat \\
\hline Motor suspension \\
Anti-rolling rod seat
\end{tabular}

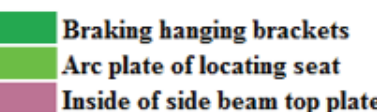

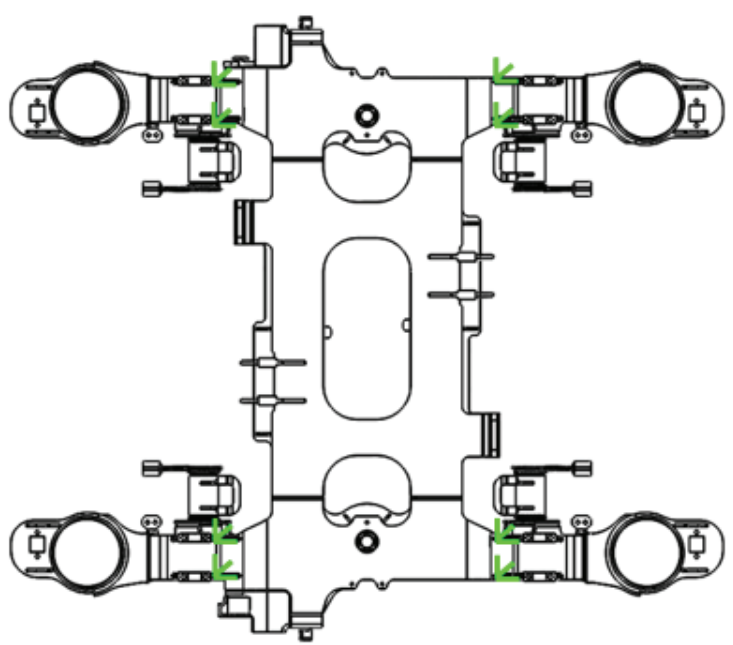

Outside of side beam top plate Reinforcing plate of lateral stop Reinforcing plate of gearbox seat

Figure 12. Measuring points diagram of bogie frame

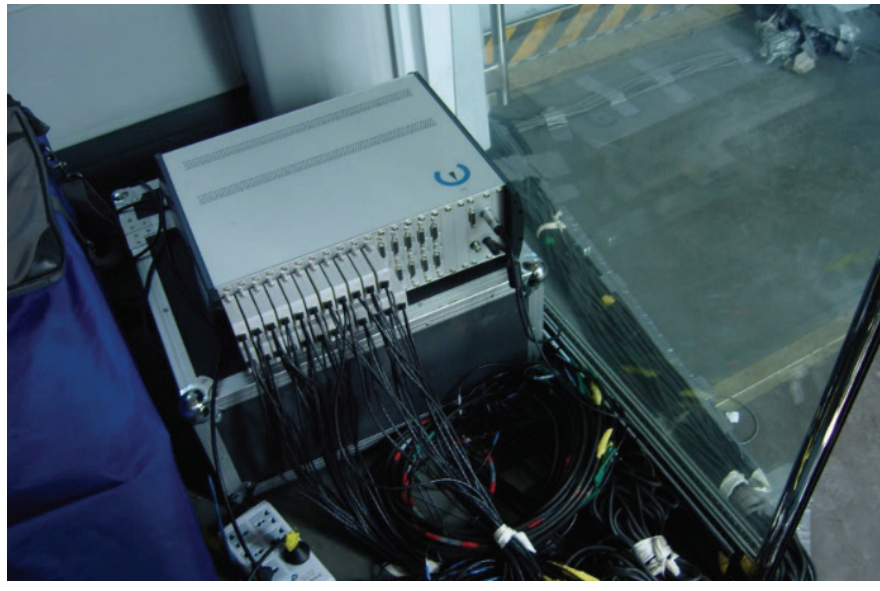

Figure 13. Data acquisition system

Figure 14. Location plan of the tested bogie frame.

od is used to process the time domain data. Table 6 is statistical counting result of one of the gearbox seat me- asuring point.

For the structure, the measured dynamic stress time history is often a subsample of limited length so that the dynamic stress spectrum cannot be directly used for fatigue strength evaluation. A feasible method is to carry on the statistical inference to get dynamic stress extension spectrum which contains the possible maximum value during the period of service. It is necessary to do the distribution fitting of measured dynamic stress spectrum before statistical inference. There are some common types of distribution such as truncated normal distribution, lognormal distribution and Weibull distribution. Through different values of shape parameter, the shape of Weibull distribution changes a lot

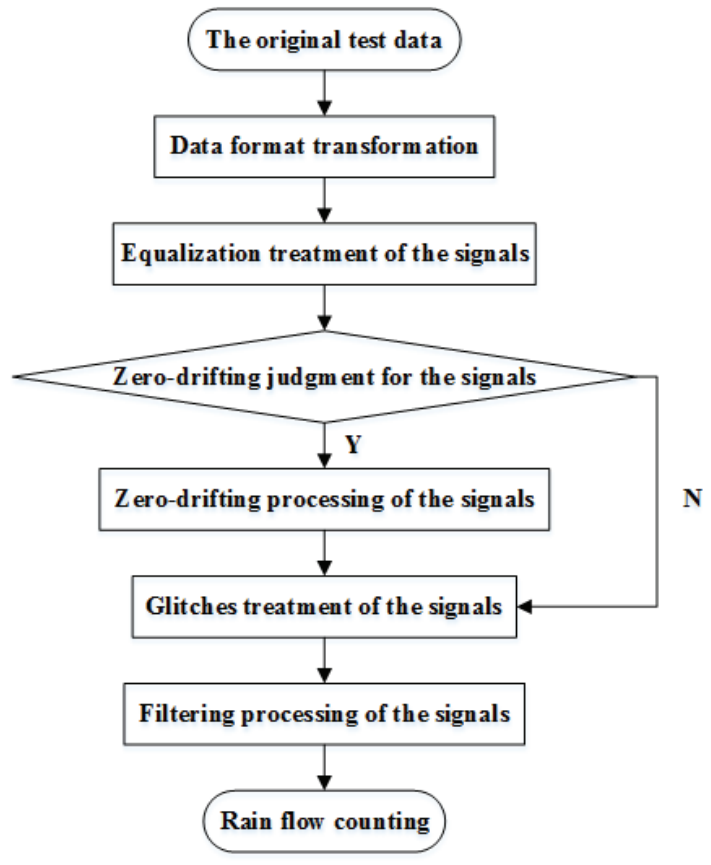

Figure 15. The flow chart of data processing.

and has a strong adaptability. Lognormal distribution has a good adaptability when the data distribution is uneven and high-low amplitude areas vary widely. In order to ha- ve a combination benefits of these two types of distribution, this paper combines the two types of distribution to become a new kind of distribution which is called combined distribution. The probability density function is set as follows:

$$
f(x)=\frac{1}{K_{n}}\left[\varphi f(x)_{1}+(1-\varphi) f(x)_{2}\right]
$$

The data in Table 6 is fitted by using of the combined distribution. The fitting curve and frequency distribution histogram are shown together in Figure 16. 
Table 6: The rain flow count results of a gearbox seat measuring point.

\begin{tabular}{lll}
\hline Level & Class midpoint (MPa) & Frequency \\
\hline 1 & 6.73 & 378678 \\
2 & 10.19 & 208683 \\
3 & 13.66 & 98715 \\
4 & 17.12 & 42743 \\
5 & 20.58 & 17472 \\
6 & 24.05 & 7305 \\
7 & 27.51 & 3006 \\
8 & 30.97 & 1301 \\
9 & 34.43 & 618 \\
10 & 37.9 & 292 \\
11 & 41.36 & 148 \\
12 & 44.82 & 80 \\
13 & 48.29 & 50 \\
14 & 51.75 & 25 \\
15 & 55.21 & 18 \\
16 & 60.41 & 8 \\
17 & 70.8 & 8 \\
\hline
\end{tabular}

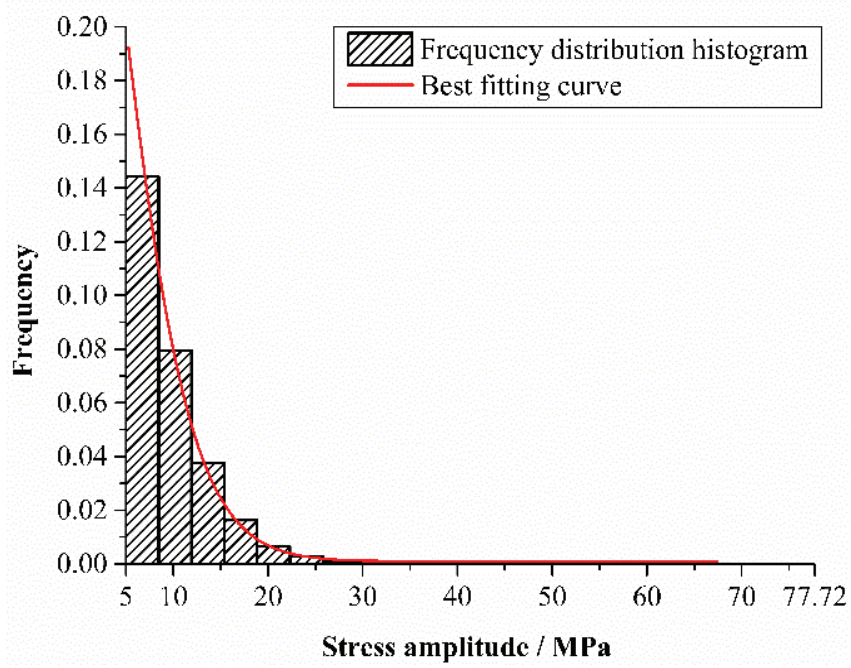

Figure 16. Frequency distribution histogram and fitting curve.

As can be visually seen from Figure 16, the fitting curve and frequency distribution histogram match very well.

\subsubsection{The extension of stress spectrum and damage calculation}

Due to the limited sample size of the dynamic stress time history data, it is necessary to do statistical inference to get the maximum stress value. According to ${ }^{[9]}, 10^{-6}$ should be seen as the maximum stress's probability of occurrence. The maximum stress that may occur during service period can be gotten by reverse solving the distribution function under the help of exceedance probability.

In this paper, the inferred maximum stress value is 81.13 $\mathrm{MPa}$ which is slightly larger than the measured maximum 77.72MPa. In order to get the measured extension spectrum, all levels of the measured spectrum need to be multiplied by a coefficient so that the total cycles can reach $10^{-6}$. The minimum value of extension spectrum is also $5 \mathrm{MPa}$. The inferred results are shown in Table 7.

The damage can be calculated according to the extension spectrum of combined distribution. The calculation of damage is on the basis of Miner linear cumulative damage rule ${ }^{[10]}$. Considering the parameters of S-N curve, the formula can be modified as (17):

$$
D=\sum_{i=1}^{17} \frac{n_{i}}{N_{i}}=\sum_{i=1}^{17} \frac{n_{i} \sigma_{-1 i}^{m}}{C_{3}}
$$

Table 7: Comparison of measured spectrum and extended spectrum.

\begin{tabular}{lllll}
\hline & \multicolumn{2}{c}{ Measured spectrum } & \multicolumn{2}{c}{ Extended spectrum } \\
\cline { 2 - 5 } Level & $\begin{array}{c}\text { Amplitude } \\
(\mathrm{MPa})\end{array}$ & Frequency & $\begin{array}{c}\text { Amplitude } \\
(\mathrm{MPa})\end{array}$ & Frequency \\
1 & 6.73 & 498818 & 7.24 & 532654 \\
2 & 10.19 & 274890 & 11.72 & 262792 \\
3 & 13.66 & 130034 & 16.20 & 112365 \\
4 & 17.12 & 56304 & 20.68 & 54256 \\
5 & 20.58 & 23015 & 25.16 & 22351 \\
6 & 24.05 & 9623 & 29.64 & 8659 \\
7 & 27.51 & 3960 & 34.12 & 3754 \\
8 & 30.97 & 1714 & 38.60 & 1615 \\
9 & 34.43 & 814 & 43.08 & 789 \\
10 & 37.9 & 385 & 47.56 & 401 \\
11 & 41.36 & 195 & 52.04 & 156 \\
12 & 44.82 & 105 & 56.52 & 95 \\
13 & 48.29 & 66 & 61.00 & 53 \\
14 & 51.75 & 33 & 65.48 & 29 \\
15 & 55.21 & 24 & 69.96 & 22 \\
16 & 60.41 & 11 & 74.44 & 6 \\
17 & 70.80 & 11 & 78.92 & 3 \\
\hline
\end{tabular}

Design using mileage of the high-speed train is 12 million kilometers. According to Miner linear cumulative damage rule, Structure fatigue fracture will occur when the total damage equal to 1 . That is to say, the total railway operation mileage is 12 million kilometers. However, the damage calculated by (15) is the damage that train runs 2636 kilometers. To dete-

rmine whether fatigue failure of each measuring point will happen when the train run 12 million kilometers, the measured damage should be converted to equivalent damage that train runs 12 million kilometers. Assuming that damage is proportional to train running mileage, then measured damage and equivalent damage can be listed as Table 8 .

As can be seen from Table 8, equivalent damage values of all the frame measuring points are all less than 1. In addition, measuring points with the same types have damage value with the same order of magnitude. 
Table 8: Measured damage value and equivalent damage value of each measuring point.

\begin{tabular}{llll}
\hline No. & Location & $\begin{array}{l}\text { Measured } \\
\text { damage }\end{array}$ & $\begin{array}{l}\text { Equivalent } \\
\text { damage }\end{array}$ \\
\hline 1 & Traction rod seat & $3.10 \mathrm{E}-07$ & $1.41 \mathrm{E}-03$ \\
2 & $5.20 \mathrm{E}-07$ & $2.36 \mathrm{E}-03$ \\
3 & Motor suspension & $7.70 \mathrm{E}-06$ & $3.50 \mathrm{E}-02$ \\
4 & $7.70 \mathrm{E}-06$ & $3.50 \mathrm{E}-02$ \\
5 & Anti-rolling rod & $1.20 \mathrm{E}-07$ & $5.45 \mathrm{E}-04$ \\
6 & seat & $1.20 \mathrm{E}-07$ & $5.45 \mathrm{E}-04$ \\
7 & & $4.20 \mathrm{E}-08$ & $1.91 \mathrm{E}-04$ \\
8 & Braking hanging & $2.20 \mathrm{E}-08$ & $1.00 \mathrm{E}-04$ \\
9 & brackets & $4.70 \mathrm{E}-08$ & $2.14 \mathrm{E}-04$ \\
10 & & $3.20 \mathrm{E}-08$ & $1.45 \mathrm{E}-04$ \\
11 & & $2.20 \mathrm{E}-05$ & $1.00 \mathrm{E}-01$ \\
12 & & $6.20 \mathrm{E}-05$ & $2.82 \mathrm{E}-01$ \\
13 & & $3.70 \mathrm{E}-05$ & $1.68 \mathrm{E}-01$ \\
14 & Arc plate of locat- & $4.50 \mathrm{E}-05$ & $2.05 \mathrm{E}-01$ \\
15 & ing seat & $3.40 \mathrm{E}-05$ & $1.55 \mathrm{E}-01$ \\
16 & & $3.80 \mathrm{E}-05$ & $1.73 \mathrm{E}-01$ \\
17 & & $3.40 \mathrm{E}-05$ & $1.55 \mathrm{E}-01$ \\
18 & & $5.50 \mathrm{E}-05$ & $2.50 \mathrm{E}-01$ \\
19 & & $8.20 \mathrm{E}-07$ & $3.73 \mathrm{E}-03$ \\
20 & Inside of side & $5.20 \mathrm{E}-07$ & $2.36 \mathrm{E}-03$ \\
21 & beam top plate & $3.40 \mathrm{E}-07$ & $1.55 \mathrm{E}-03$ \\
22 & & $8.40 \mathrm{E}-07$ & $3.82 \mathrm{E}-03$ \\
23 & Outside of side & $2.70 \mathrm{E}-06$ & $1.23 \mathrm{E}-02$ \\
24 & beam top plate & $3.70 \mathrm{E}-06$ & $1.68 \mathrm{E}-02$ \\
25 & Reinforcing plate & $7.70 \mathrm{E}-06$ & $3.50 \mathrm{E}-02$ \\
26 & of lateral stop & $6.90 \mathrm{E}-06$ & $3.14 \mathrm{E}-02$ \\
& Reinforcing plate & $2.20 \mathrm{E}-06$ & $1.00 \mathrm{E}-02$ \\
& $7.20 \mathrm{E}-06$ & $3.27 \mathrm{E}-02$ \\
\hline
\end{tabular}

\section{Summary}

In this paper, finite element simulation and fatigue test rig are implemented to assess static strength and fatigue strength of a bogie frame. In addition, actual running test was also operated to assess fatigue strength of the frame. The results show that static strength of the tested bogie frame meets requirements. For the measured dynamic stress data, Miner linear cumulative damage rule seems to be very effective when judging fatigue strength of the frame. All the above methods have proved that fatigue strength of the tested bogie frame meets requirement.

\section{References}

[1] EN 13749: railway applications - methods of specifying structural requirements of bogie frames. CEN Brussels; 2005.

[2] UIC 615-4: powered vehicles-bogies and running gearstrength tests of bogie frames. Paris; 1994.

[3] JIS E 4207: design specification of railway rolling stock bogie; 2004.

[4] Jung-Seok Kim. Fatigue assessment of tilting bogie frame for Korean tilting train: Analysis and static tests. Engineering Failure Analysis. 13 (2006) 1326-1337.

[5] M. Kassner. Fatigue strength analysis of a welded railway vehicle structure by different methods. Int J Fatigue. 34 (2012) 103-111.

[6] Jung-Seok Kim, Nam-Po Kim. Evaluation of structural safety of a tilting bolster. Engineering Failure Analysis. 14 (2007) 63-72.

[7] Jeong-Woo Han, Jae-Dong Kim, See-Yeob Song. Fatigue strength evaluation of a bogie frame for urban maglev train with fatigue test on full-scale test rig. Engineering Failure Analysis 31 (2013) 412-420.

[8] Bin Xiang, Jianping Shi, Lingyan Guo, Xuewen Liu, Shuhua Liu, Jizhong Lin. Plotting and application of Goodman fatigue limit diagram of railway common materials. China Railway Science. 23 (2002) 72-76.

[9] Dangxiang YI, Guozhi LV, Xiongwei ZHOU. Maximal loading calculation for two dimensional fatigue design spectrum under multiple working conditions with probability extrapolation method. Chinese Journal of Applied Mechanics, 03 (2006) 484-487+517.

[10] Miner M A. Cumulative damage in fatigue. J Appl Mech, 12(3) (1945) 159-164. 